\title{
Impact of weight on stone-free rate during percutaneous nephrolithotomy
}

\author{
Abdrabuh M. Abdrabuh* (1)
}

\begin{abstract}
Background: To assess Impact of weight on stone-free rate during percutaneous nephrolithotomy.

Methods: Hundred and twenty-three PNL procedures were done between January 2016 and July 2017. The patients were divided into four groups according to the World Health Organization (WHO) classification of body mass index (BMI): <25 ((group 1, average)), 25-29.9 (group 2, overweight), 30-39.9 (group 3, obese), and $\geq 40 \mathrm{~kg} / \mathrm{m}^{2}$ (group 4, morbidly obese). All groups were compared as regarding preoperative variables, intra-operative procedure and postoperative results.
\end{abstract}

Results: The non-obese groups were younger in age than obese and morbid obese groups $(P=0.005)$. The difference in BMI was statistically significant between non-obese and obese groups $(P=0.0001)$. Most of females gender were obese and morbid obese $(P=0.0001)$ and most of the obese patients had left-sided renal stone $(P=0.001)$. Most of overweight and obese groups had radiopaque stones $(P=0.02)$. There were no statistically significant differences between all groups as regarding co-morbidity, stone size, stone locations, and hydronephrosis grade. Operative time $(P=0.034)$, length of hospital stay $(P$ value $=0.014)$ and fluoroscopy time $(P=0.0001)$ were statistically significant differences between all groups. Number of accesses, access site, postoperative hemoglobin drop, post- operative complications, fate of residual stones and stone-free rate were not statistically significant differences between all groups. BMI was correlated with mean fluoroscopy time and mean hospitalization duration in our study as the time of hospitalization and time of $\mathrm{x}$-ray exposure increase with obesity.

Conclusion: PNL is a safe and effective procedure for obese patients. BMI do not predict clearance post PNL.

Keywords: Percutaneous nephrolithotomy, Obesity, Safety, Efficacy, Outcome

\section{Background}

The incidence of renal stone is increased with obesity and overweight, than in average weight populations [1, 2]. The main causes were hypertension, diabetes mellitus and metabolic syndrome which more increased with obesity [3]. Obesity is associated with more cardiac, pulmonary and wound complications that is lead to increase percentage of morbidity and mortality in this category of population $[4,5]$. Multiple procedures are available for management of renal stones including extra-corporeal shock wave lithotripsy (ESWL), retrograde intrarenal

*Correspondence: abdo197871@yahoo.com

Urology Department, Al-Azhar University Hospitals, Cairo, Egypt surgery (RIRS) and percutaneous nephrolithotomy (PNL). Obesity is an independent factor predicting failure of renal stone fragmentation post ESWL because of long skin to stone distance, difficulty to localize the stone either by fluoroscopy or ultrasound and the burden of large stones obstructing the urinary system. The success of RIRS is dependent on multiple factors such as stone size, stone number, stone location and surgeon experience $[6,7]$. Percutaneous nephrolithotomy (PNL) is the most effective procedure for management of renal stones especially if the stone size is more than $2 \mathrm{~cm}$. PNL is one of the most available therapeutic modalities for obese patients [8]. The role of this study is to assess the impact of weight on stone-free rate during PNL. 


\section{Methods}

One hundred and twenty-three PNL procedures were done during the period from January 2016 to July 2017 and the results were analyzed prospectively. The study was conducted by urology department, at a tertiary academic medical center in Egypt and local ethical committee approved the study and all patients provided a written informed consent before inclusion. The study included all patients of either gender or aged above 18 years with stone size $\geq 2 \mathrm{~cm}$. All patients $(<18$ years), with active UTI, patients with congenital renal anomalies and patients with coagulopathy were excluded from the study. The patients were divided into four groups according to the World Health Organization (WHO) classification of body mass index (BMI) [9]: $<25$ (group 1, average), 25-29.9 (group 2, overweight), 30-39.9 (group 3, obese), and $\geq 40 \mathrm{~kg} / \mathrm{m}^{2}$ (group 4, morbidly obese). The studied patients were evaluated preoperatively with full medical history including sex, age, and laterality. Complete physical examination including body mass index (BMI). All patients were evaluated preoperatively with Laboratory tests (CBC, RBG, Kidney function tests, Liver function tests and coagulation profile, Urine analysis and urine culture). Radiological investigations included KUB to detect radiopaque stones. Pelvic-abdominal ultrasound and non-contrast CT (NCCT) of the urinary tract to provide a picture of the stone complexity were measured by professional radiologist. Intra-operative and postoperative results were also compared between all groups. The calyceal involvements of stones were divided into three groups: group (1) stone in the renal pelvis, upper ureter, or in one caylex. Group (2) stone involved more than two calyces or partial stag horn stone. Group (3) stone involved all calyces (complete stag horn stone). The stone size was defined as widest diameter in centimeter. All procedures were done with expert urologist in high-volume medical center. Prophylactic intravenous antibiotic in form of cephalexin 2 days before surgery was injected.

\subsection{PNL technique}

First, a lithotomy position was done. Insertion of A 6 Fr. Ureteric catheter through the $21 \mathrm{Fr}$. Cystoscope to the ipsilateral ureter. A 16 Fr. Foley catheter was inserted. The patient was then changed to a prone position. A contrast material was injected through open tip ureteric catheter to opacify the pelvicalyceal system. A puncture needle was inserted into renal calyx under fluoroscopic guidance which confirmed by re-aspiration of urine through the sensor of the puncture needle. A .035-inch flexible tip guide wire was inserted through the puncture needle. The tract was dilated with fascial dilators up to $12 \mathrm{Fr}$. Which were facilitated by passing them over the guide wire. In obese and morbidly obese patients, skin incision was done to the level of abdominal fascia to gain extra length to reach the stone. In case of inter-costal approach, the respiration is holded in full expiration until the needle advanced through the calyceal system. Multiple tracts were done in some cases according to complexity of stone and surgeon experience. The tract was further dilated with Amplatz dilators up to 28 Fr. A30 Fr. Amplatz sheath was installed and a nephroscope was inserted. In obese patients, the long instruments were used such as long Amplatz sheath and long nephroscope to facilitate access to the stone for disintegration and extraction. Normal saline was used for irrigation. The instrument was passed to the level of the stone. The stone in the calyx was fragmented with pneumatic lithotripsy, and the stone fragments were removed by grasper. If no calculi appeared with nephroscope or fluoroscopic inspection, the operation finished. In some cases, Double-J catheter was inserted from the renal pelvis to the urinary bladder due to renal pelvis perforation or inaccessible stones need other intervention such as ESWL. The position of double-J was checked by the fluoroscopy. At the same time, the previous ureteral catheter was removed. A20 Fr. Percutaneous nephrostomy tube was left in place. Nephrostomy tube clamped at the 2nd postoperative day and urethral catheter removed. If no fever, pain or leakage, then nephrostomy tube removed. Patient was evaluated on day 2 postoperatively with (KUB) X-ray and/or ultrasound to detect radiopaque and radio-lucent stone. All patients were re-evaluated one month post PNL with KUB and ultrasound or CT scan for detection of stone clearance between all groups of patients. All patients with complete stone clearance or had clinical insignificant residual fragments (CIRF) less than $4 \mathrm{~mm}$ were considered stone free. In obese and morbid obese patients, special precautions should be done such as, any cardiac or pulmonary problem should controlled before surgery, PNL in supine position is preferable, intra-operative monitoring of the arterial blood gases and blood pressure should be done and postoperative ICU admission according to the surgical requirement and concomitant diseases.

\subsection{Statistical analysis}

Statistical analyses of data were done between all groups. Quantitative data were expressed as mean \pm standard deviation (SD). Qualitative data were expressed as frequency and percentage. One-way analysis of variance (ANOVA) was used to differentiate the 4 groups of BMI. Categorical variables were analyzed by Kruskal-Wallis test; respectively, $P$ value $<0.05$ had a significant difference. Pearson correlation test analyzed the relationships between variables. Data were analyzed using Statistical 
Program for Social Science (SPSS Inc., Chicago, IL, USA) version 20.0.

\section{Results}

A total 123 procedures were done in one institution between January 2016 and July 2017 consisting of 71 (57.7\%) males and $52(42.3 \%)$ females with a mean age $43.85 \pm 11.58$ (19-67) years. The non-obese group was younger in age than obese and morbid obese groups $(P=0.005)$. The overall main BMI was $28.6 \pm 5.007 \mathrm{~kg} /$ $\mathrm{m}^{2}$ (range: $\left.21.7-43.7\right)$. Among 123 patients, we found 40 (32.5\%) with average BMI, 45 (36.6\%) with overweight, 34 (27.6\%) with obesity, and 4 (3.3\%) to be morbidly obese. BMI was statistically significant between all groups $(P=0.0001)$. Of 123 patients, $15(12.19 \%)$ patients had one co-morbidity in addition to obesity and 7 (5.69\%) patients had two co-morbidities. Most of females gender were obese and morbid obese $(P=0.0001)$ and most of obese patients had LT sided renal stone $(P=0.001)$. Most of overweight and obese groups had radiopaque stones $(P=0.02)$ There were no statistically significant difference between all groups as regarding co-morbidity, stone size, stone locations, and hydronephrosis grade as shown in Table 1.

The mean fluoroscopy time was $8.07 \pm 4.41$ (4-20) minutes and operative time was 53 (41-220) minutes. There were statistical significant differences between all groups as regarding operative time $(P=0.034)$, and fluoroscopy time $(P=0.0001)$. A total 180 percutaneous accesses were required for 123 renal units (average 1.4 accesses per renal unit). Lower calyces punctures were done in 87 (70.7\%) renal units, middle calyces in 13 (10.5\%) and upper calyces were done in $2(1.6 \%)$ renal units. Multiple accesses were done in 21 (17.07\%) renal units. There were no statistical significant difference between all groups as regarding number of accesses and access site as shown in Table 2.

The mean length of hospital stay was $4.26 \pm 1.52$ (3-10) days. There were statistical significant differences between all groups as regarding length of hospital stay $(P$-value $=0.014)$. The length of hospital stay was correlated with postoperative complications and time of its management. There were no statistical significant differences between all groups as regarding postoperative

Table 1 Analysis of preoperative variables

\begin{tabular}{|c|c|c|c|c|c|c|c|c|c|}
\hline & Group 1 & (\%) & Group 2 & (\%) & Group 3 & (\%) & Group 4 & (\%) & $P$-value \\
\hline & average $(<25)$ & & Overweight (25-29.9) & & Obese (30-39.9) & & Morbid obese (>40) & & \\
\hline Count (123) & 40 & 32.5 & 45 & 36.6 & 34 & 27.6 & 4 & 3.3 & \\
\hline Gender, \% & & & & & & & & & 0.0001 \\
\hline Male (71) & 29 & 72.5 & 34 & 75.5 & 8 & 23.5 & 0 & 0 & \\
\hline Female (52) & 11 & 27.5 & 11 & 24.5 & 26 & 76.5 & 4 & 100 & \\
\hline Age $($ mean $\pm S D)$ & $39.07 \pm 13.94$ & & $44.04 \pm 9.71$ & & $48.17 \pm 9.18$ & & $52.50 \pm 1.73$ & & 0.005 \\
\hline $\begin{array}{l}\text { Body Mass Index (kg/m²) } \\
\text { median(range) }\end{array}$ & $23.8(21.7-29.4)$ & & $27.7(25-29.7)$ & & $33.4(30-38.8)$ & & $42.1(40.5-43.7)$ & & 0.0001 \\
\hline Comorbidity & & & & & & & & & 0.224 \\
\hline HTN (9) & 3 & 7.5 & 2 & 4.45 & 2 & 5.88 & 2 & 50 & \\
\hline DM (6) & 2 & 5 & 4 & 8.89 & 0 & 0 & 0 & 0 & \\
\hline HTN + DM (7) & 0 & 0 & 2 & 4.45 & 5 & 14.7 & 0 & 0 & \\
\hline (mean $\pm S D)$ & $2.1 \pm .12$ & & $2.4 \pm .4$ & & $2.3 \pm .15$ & & $2.4 \pm .34$ & & 0.378 \\
\hline Stones Localization & & & & & & & & & 0.184 \\
\hline 1 OR 2 Calyces (86) & 30 & 75 & 32 & 71.2 & 20 & 58.8 & 4 & 100 & \\
\hline Multiple calyces (18) & 8 & 20 & 4 & 8.8 & 6 & 17.6 & 0 & 0 & \\
\hline Stag horn (19) & 2 & 5 & 9 & 20 & 8 & 23.5 & 0 & 0 & \\
\hline Side & & & & & & & & & 0.001 \\
\hline Left (64) & 15 & 37.5 & 19 & 42.3 & 28 & 82.3 & 2 & 50 & \\
\hline Right (59) & 25 & 62.5 & 26 & 57.7 & 6 & 17.7 & 2 & 50 & \\
\hline Hydronephrosis & & & & & & & & & 0.146 \\
\hline (None, mild) (82) & 28 & 70 & 25 & 55.5 & 25 & 73.5 & 4 & 100 & \\
\hline (Moderate, Severe) (41) & 12 & 30 & 20 & 44.5 & 9 & 26.5 & 0 & 0 & \\
\hline Essence' $(H U)$ & & & & & & & & & 0.020 \\
\hline Non- opaque(43) & 21 & 52.5 & 12 & 26.6 & 8 & 23.5 & 2 & 50 & \\
\hline Opaque(80) & 19 & 47.5 & 33 & 73.4 & 26 & 76.5 & 2 & 50 & \\
\hline
\end{tabular}

$P<0.05$ are in italics 
Table 2 Analysis of intra-operative variables

\begin{tabular}{|c|c|c|c|c|c|c|c|c|c|}
\hline & Group 1 & (\%) & Group 2 & (\%) & Group 3 & (\%) & Group 4 & (\%) & $P$-value \\
\hline & Average $(<25)$ & & Overweight (25-29.9) & & Obese (30-39.9) & & Morbid obese (>40) & & \\
\hline Patients count(123) & 40 & & 45 & & 34 & & 4 & & \\
\hline $\begin{array}{l}\text { Operative time(min) } \\
\text { Median(range) }\end{array}$ & $46(41-213)$ & & $53(41-220)$ & & $61(42-215)$ & & $45(43-55)$ & & 0.034 \\
\hline $\begin{array}{l}\text { Fluoroscopy time(minutes) } \\
\text { Median(range) }\end{array}$ & $5(3.8-20)$ & & $5.30(4.30-20)$ & & $9(5.8-17)$ & & $12(6-13)$ & & 0.0001 \\
\hline Number of access & & & & & & & & & 0.134 \\
\hline $1(86)$ & 31 & 77.5 & 31 & 68.9 & 20 & 58.8 & 4 & 100 & \\
\hline $2(17)$ & 7 & 17.5 & 4 & 8.8 & 6 & 17.7 & 0 & 0 & \\
\hline $3(20)$ & 2 & 5 & 10 & 22.3 & 8 & 23.5 & 0 & 0 & \\
\hline Access site & & & & & & & & & 0.066 \\
\hline Multiple (21) & 4 & 10 & 5 & 11.1 & 11 & 32.4 & 1 & 25 & \\
\hline Upper calyces (2) & 1 & 2.5 & 0 & 0 & 1 & .95 & 0 & 0 & \\
\hline Middle calyces (13) & 2 & 5 & 8 & 17.8 & 3 & 8.8 & 0 & 0 & \\
\hline Lower calyces (87) & 33 & 82.5 & 32 & 71.1 & 19 & 55.9 & 3 & 75 & \\
\hline
\end{tabular}

$P<0.05$ are in italics

hemoglobin drop, postoperative complications, fate of residual stones and stone-free rate. The most common postoperative complications were transient leak in 9 (7.31\%) which were managed conservatively. Persistent leakage was observed in $2(1.63 \%)$ cases which were managed with retrograde DJ stent insertion. Postoperative anemia was observed in 4 (3.25\%) cases which were managed by blood transfusion. Colonic injury was observed in one case which was managed conservatively by withdrawal of nephrostomy tube outside the kidney and colon to retro peritoneal spaces, retrograde DJ stent insertion, parenteral nutrition, low residual diet, and prophylactic antibiotic in form of cephalosporin and metronidazole for 7 days. SFR in average weight group was $82.5 \%$, in over weight group was $84.5 \%$, in obese group was $76.5 \%$ and in morbid obese group was $100 \%$. Significant residual stones were observed in 22 (17.8\%) renal units, in whom 8 renal units underwent 2nd look PNL due to multiple residual stones (ranges $10-15 \mathrm{~mm}$ ), 2 renal units underwent open nephrolithotomy one week post PNL due to multiple large inaccessible residual stones, 10 renal units for ESWL (stones burden ranges $6-10 \mathrm{~mm}$ ) and 2 renal units (stones burden $>6 \mathrm{~mm}$ ) for follow-up. There were no statistical significant differences between all groups as regarding postoperative hemoglobin drop, post- operative complications, fate of residual stones and stone-free rate as shown in Table 3.

BMI was correlated well with mean fluoroscopy time and mean hospitalization duration in our study as the time of hospitalization and time of $x$-ray exposure increase with obesity as shown in Table 4.

\section{Discussion}

Obesity is a major risk factor for many chronic diseases such as ischemic heart diseases, diabetes mellitus, hypertension, and urolithiasis [9]. Multiple factors are responsible for association between stone formation and obesity such as increase in carbohydrate and purine intake, increase in insulin resistance and its effect on metabolism of ammonia, increase prevalence of gout and change in renal cell transport [9]. ESWL is not efficient in treating renal stone in obese patients. RIRS with laser therapy is an alternative option for renal stone fragmentation [7].

In obese patients with large renal stones, PNL is the better method of treatment [10]. PNL is usually performed in prone position but in obese and morbid obese patients this can compromise respiratory and circulatory functions, so lateral decubitus and supine PNL are alternatives [11-13]. PNL under assisted local anesthesia was an alternative technique to general anesthesia to overcome the complications done in morbid obese patient such as retention in carbon dioxide and difficulty in weaning of ventilation postoperatively $[14,15]$.

In our study, 123 patients underwent PNL by one expert urologist in one high-volume medical center. There were no statistically significant difference between all groups as regarding co-morbidity, stone size, stone locations, and hydronephrosis grade, number of accesses and access site. There were statistical significant differences between all groups as regarding operative time, and fluoroscopy time and length of hospital stay. There were no statistical significant differences between all groups as regarding hemoglobin 
Table 3 Analysis of postoperative variables

\begin{tabular}{|c|c|c|c|c|c|c|c|c|c|}
\hline & Group 1 & (\%) & Group 2 & (\%) & Group 3 & (\%) & Group 4 & (\%) & $P$-value \\
\hline & Average $(<25)$ & & $\begin{array}{l}\text { Overweight } \\
(25-29.9)\end{array}$ & & Obese (30-39.9) & & Morbid obese $(>40)$ & & \\
\hline Patients count(123) & 40 & & 45 & & 34 & & 4 & & \\
\hline Hospitalization duration (days) & & & & & & & & & 0.014 \\
\hline Median(range) & $4(3-5)$ & & $4(3-10)$ & & $4(3-7)$ & & $5.5(4-7)$ & & \\
\hline Hemoglobin drop (g/dl) & & & & & & & & & 0.094 \\
\hline Median(range) & $.95(0-2)$ & & $1(0-4)$ & & $1.05(1-4)$ & & $.95(1-4)$ & & \\
\hline Postoperative complications & & & & & & & & & 0.833 \\
\hline Anemia(4) & 2 & 5 & 2 & 4.4 & 0 & 0 & 0 & 0 & \\
\hline Leakage < 24 h(9) & 3 & 7.5 & 3 & 6.7 & 3 & 8.8 & 0 & 0 & \\
\hline Persistent leakage > 24 h(2) & 0 & 0 & 0 & 0 & 2 & 5.8 & 0 & 0 & \\
\hline Colonic injury(1) & 1 & 2.5 & 0 & 0 & 0 & 0 & 0 & 0 & \\
\hline Postoperative DJ insertion (8) & 4 & 10 & 2 & 4.4 & 2 & 5.8 & 0 & 0 & 0.704 \\
\hline Fate of residual stones & & & & & & & & & 0.366 \\
\hline $\operatorname{ESWL}(10)$ & 7 & 17.5 & 1 & 2.2 & 2 & 5.8 & 0 & 0 & \\
\hline 2nd look(8) & 0 & 0 & 2 & 4.4 & 6 & 17.6 & 0 & 0 & \\
\hline Open surgery(2) & 0 & 0 & 2 & 4.4 & 0 & 0 & 0 & 0 & \\
\hline Follow-up (2) & 1 & 2.5 & 1 & 2.2 & 0 & 0 & 0 & 0 & \\
\hline Results & & & & & & & & & 0.623 \\
\hline $\begin{array}{l}\text { Number of patients with residual } \\
\text { stones(22) }\end{array}$ & 7 & 17.5 & 7 & 15.5 & 8 & 23.5 & 0 & 0 & \\
\hline $\begin{array}{l}\text { Number patients with stone-free } \\
\text { status(101) }\end{array}$ & 33 & 82.5 & 38 & 84.5 & 26 & 76.5 & 4 & 100 & \\
\hline
\end{tabular}

Table 4 Correlation between BMI and operation outcome (univariate and multivariate analysis)

\begin{tabular}{lcl}
\hline & BMI & P values \\
\hline Mean operative time (min) & .156 & 0.085 \\
Mean fluoroscopy time (minutes) & .391 & 0.000 \\
Mean hospitalization duration (days) & .291 & 0.001 \\
Mean hemoglobin drop (g/dl) & .141 & 0.121 \\
Postoperative complications & .036 & 0.696 \\
\hline
\end{tabular}

drop, post- operative complications, fate of residual stones and stone-free rate. BMI was correlated well with mean fluoroscopy time and mean hospitalization duration in our study as the time of hospitalization and time of $x$-ray exposure increase with obesity.

In the retrospective study of Faeber et al. on 530 patients [16] concluded that BMI had no role in clearance of stone between obese and non-obese patients, but the complications rate was more (37\% vs. $17 \%)$ in morbid obese group than in non-obese group, but the time of hospitalization and time of $\mathrm{x}$-ray exposure increase with obesity. These results are comparable with our results.
In the study of Pearle et al. [17] showed that in 57 patients with a BMI of $>30 \mathrm{~kg} / \mathrm{m}^{2}$, the operative time was slightly longer but outcomes in terms of stone-free and complication rates were not different compared to 179 patients with a BMI of $<30 \mathrm{~kg} / \mathrm{m}^{2}$. These results are comparable with our results.

In another studies [18-20] there were no significant differences among groups categorized by the World Health Organization (WHO) classification of BMI as regarding of SFR, hospital stay, and complication rate as shown in Table 5. In a prospective study of Ortiz et al. [21] on 255 patients, reported that no significant difference between all groups classified with WHO classification of BMI as regarding the total operative time and radiation time increases along with BMI. This may be explained by the higher stone burden in obese patients and more difficult body habitus for percutaneous access.

In the large multi center database prospective study done on 5803 patients, the Clinical Research Office of the Endourological Society (CROES) result is as different to our study as SFR is decreased and operative time is increased with obesity if compared to normal BMI group [22]. In The CROES study, the stag horn stone and calyx involved were significantly more in the super obese group. Also SFR is significantly increased in high-volume 
Table 5 Summary of effect of body mass index in percutaneous nephrolithotripsy

\begin{tabular}{|c|c|c|c|c|c|c|c|c|c|}
\hline Study & Number & $\begin{array}{l}\text { Study } \\
\text { design }\end{array}$ & $\begin{array}{l}\text { Clearance } \\
\text { (SFR) }\end{array}$ & OR. time & $\begin{array}{l}\text { Hospital } \\
\text { stay }\end{array}$ & Complications & $\begin{array}{l}\text { Blood } \\
\text { transfusion }\end{array}$ & $\begin{array}{l}\text { Analgesic } \\
\text { use }\end{array}$ & Auxiliaryprocedure \\
\hline Faeber [16] & 530 & $\begin{array}{l}\text { Retrospective } \\
\text { Normal } \\
\text { Morbidity } \\
\text { obesity }\end{array}$ & $=$ & $\uparrow$ & $\uparrow$ & $\uparrow$ & & & \\
\hline $\begin{array}{l}\text { Pearle (2 } \\
\text { institutions) } \\
\text { [17] }\end{array}$ & 236 & $\begin{array}{l}\text { Retrospective } \\
\text { BMI: } \geq 30 \\
\text { Non select- } \\
\text { edseries }\end{array}$ & $=$ & $=$ & $=$ & $=$ & $=$ & & \\
\hline $\begin{array}{l}\text { Koo (1 sur- } \\
\text { geon) [18] }\end{array}$ & 223 & $\begin{array}{l}\text { Retrospective } \\
\text { BMI: }<25 \\
25-29, \\
30-39, \geq 40\end{array}$ & $=$ & $=$ & $=$ & $=$ & & $=$ & \\
\hline $\begin{array}{l}\text { El-Assmy (1 } \\
\text { institution) } \\
{[19]}\end{array}$ & 1211 & $\begin{array}{l}\text { Retrospective } \\
\text { BMl: }<25 \\
25-29 \\
30-39, \geq 40\end{array}$ & $=$ & $=$ & $=$ & $=$ & & & $=$ \\
\hline $\begin{array}{l}\text { Bagrodia (1 } \\
\text { surgeon) } \\
{[20]}\end{array}$ & 183 & $\begin{array}{l}\text { Retrospective } \\
\text { BMl: }<25 \\
25-29 \\
30-39, \geq 40\end{array}$ & $=$ & $=$ & $=$ & $=$ & $=$ & & \\
\hline $\begin{array}{l}\text { CROES* } \\
\text { Multi-cent- } \\
\text { ers [22] }\end{array}$ & 5803 & $\begin{array}{l}\text { Prospective } \\
\text { database } \\
\text { BMl: }<25 \\
25-29 \\
30-39, \geq 40\end{array}$ & $\uparrow$ & $\uparrow$ & $=$ & $=$ & $=$ & & $\uparrow$ \\
\hline $\begin{array}{l}\text { Ortiz* (1 } \\
\text { institution) } \\
{[21]}\end{array}$ & 255 & $\begin{array}{l}\text { Prospective } \\
\text { BMl: }<25 \\
25-29, \\
30-39, \geq 40\end{array}$ & $=$ & $\uparrow$ & $=$ & $=$ & & & $=$ \\
\hline $\begin{array}{l}\text { Our study* }(1 \\
\text { surgeon) (1 } \\
\text { institution) }\end{array}$ & 123 & $\begin{array}{l}\text { Prospective } \\
\text { BMl: }<25 \\
25-29 \\
30-39, \geq 40\end{array}$ & $=$ & $\uparrow$ & $\uparrow$ & $=$ & $=$ & & \\
\hline
\end{tabular}

*Prospective study. SFR Stone-free rate, OP time Operation time, $\uparrow:$ Increase, $=:$ : No effect

centers, and super obese patients had a worse outcome independent of patient volume.

In our study, the number of stag horn stone and calyces involved are the same in all groups and over obese group had good outcome as regarding SFR and complications rate.

The limitations of our study were small sample size, little number of morbid obese patients, and no analysis of stones.

\section{Conclusion}

BMI has no effect on prediction of stone clearance post PNL. Age, BMI, laterality, stone density, operative time, time of hospitalization and time of $\mathrm{x}$-ray exposure are correlated significantly with obesity. PNL is safe and effective procedure between obese and non-obese groups done by single expert surgeon in general population.

\section{Abbreviations}

SFR: stone-free rate; CT: computed tomography; SF: stone free; Non SF: non-stone free; PNL: percutaneous Nephrolithotomy; NCCT: non-contrast computed tomography; KUB: kidney, ureter, bladder; ESWL: extra corporeal shock wave lithotripsy.

\section{Acknowledgements}

None.

\section{Authors' contributions}

'A $A$ ' is the single author who is solely responsible to the design and implementation of the research and analyzed and interpreted the patient data, performed protocol/project development, manuscript writing/editing and data analysis. Author read and approved the final manuscript.'

\section{Funding}

None.

Avaliabilty of data and material

The data-sets generated and/or analysed during the current study available from the corresponding author on reasonable request.

Ethical approval and consent to participate

Ethical approval to report these cases was obtained from the ethical and moral stipulations set by the faculty of medicine, Al-Azhar University. The ethical committee reference number is not applicable as we received the ethical 
committee report from medical research ethical committee without reference number. Written informed consent was obtained from the patient(s) for their anonymized information to be published in this article.

\section{Consent for publication}

Not applicable.

\section{Competing interests}

No conflicts of interest to be disclose.

Received: 19 May 2020 Accepted: 16 September 2020

Published online: 09 November 2020

\section{References}

1. Taylor EN, Stampfer MJ, Curhan GC (2005) Obesity, weight gain, and the risk of kidney stones. JAMA 293:455-462

2. Shavit L, Ferraro PM, Johri N, Robertson W, Walsh SB, Moochhala S et al (2015) Effect of being overweight on urinary metabolic risk factors for kidney stone formation. Nephrol Dial Transplant 30:607-613

3. Polat EC, Ozcan L, Cakir SS, Dursun M, Temur AO, Ozbek E (2015) Relationship between calcium stone disease and metabolic syndrome. Urol J 12:2391-2395

4. Flegal KM, Kit BK, Orpana H, Graubard BI (2013) Association of all-cause mortality with overweight and obesity using standard body mass index categories: a systematic review and meta-analysis. JAMA 309:71-82

5. $\quad$ Biring MS, Lewis MI, Liu JT, Mohsenifar Z (1999) Pulmonary physiologic changes of morbid obesity. Am J Med Sci 318:293-297

6. Mokhless IA, Abdeldaeim HM, Saad A, Zahran AR (2014) Retrograde intrarenal surgery monotherapy versus shock wave lithotripsy for stones 10 to $20 \mathrm{~mm}$ in preschool children: a prospective, randomized study. J Urol 191(5 suppl):1496-1499

7. El-Nahas AR, El-Assmy AM, Mansour O, Sheir KZ (2007) A multivariate analysis of factors predicting stone disintegration by extracorporeal shock wave lithotripsy: the value of high-resolution non-contrast computed tomography. Eur Urol 51:1688-1693

8. Türk C, Petřík A, Sarica K, Seitz C, Skolarikos A, Straub M et al (2016) EAU guidelines on interventional treatment for urolithiasis. Eur Urol 69:475-482

9. Calverta RC, Burgess NA (2005) Urolithiasis and obesity: metabolic and technical considerations. Curr Opin Urol 15:113-117

10. Gofrit ON, Shapiro A, Donchin Y et al (2002) Lateral decubitus position for percutaneous nephrolithotripsy in the morbidly obese or kyphotic patient. J Endourol 16:383-386
11. Valdivia Uria JG, Valle Gerhold J, Lopez Lopez JA et al (1999) Technique and complications of percutaneous nephroscopy: experience with 557 patients in the supine position. J Urol 160:1975-1978

12. Shoma A, Eraky I, Kenawy M, El-Kappany H (2002) Percutaneous nephrolithotomy in the supine position: technical aspects and functional outcome compared with the prone technique. Urology 60:388-392

13. Oberg B, Poulsen TD (1996) Obesity: an anaesthetic challenge. Acta Anaesthesiol Scand 40:191-200

14. Aravantinos E, Karatzas A, Gravas S, Tzortzis V, Melekos M (2007) Feasibility of percutaneous nephrolithotomy under assisted local anaesthesia: a prospective study on selected patients with upper urinary tract obstruction. Eur Urol 51:224-228

15. Alyami FA, Skinner TA, Norman RW (2013) Impact of body mass index on clinical outcomes associated with percutaneous nephrolithotomy. Canadian Urological Association Journal 7(3-4):E197

16. Faerber GJ, Goh M (1997) Percutaneous nephrolithotripsy in the morbidly obese patient. Tech Urol 3:89-95

17. Pearle MS, Nakada SY, Womack JS, Kryger JV (1998) Outcomes of contemporary percutaneous nephrostolithotomy in morbidly obese patients. J Urol 160:669-673

18. Koo BC, Burtt G, Burgess NA (2004) Percutaneous stone surgery in the obese: outcome stratified according to body mass index. BJU Int 93:1296-1299

19. El-Assmy AM, Shokeir AA, El-Nahas AR, Shoma AM, Eraky I, El-Kenawy MR et al (2007) Outcome of percutaneous nephrolithotomy: effect of body mass index. Eur Urol 52:199-204

20. Bagrodia A, Gupta A, Raman JD, Bensalah K, Pearle MS, Lotan Y (2008) Impact of body mass index on cost and clinical outcomes after percutaneous nephrostolithotomy. Urology 72:756-760

21. Torrecilla OC, Meza MAI, Vicens MAJ, Vila RH, Colom FS, Suarez NJF et al (2014) Obesity in percutaneous nephrolithotomy. Is body mass index really important? Urology 84:538-543

22. Fuller A, Razvi H, Denstedt JD, Nott L, Pearle M, Cauda F et al (2012) The CROES percutaneous nephrolithotomy global study: the influence of body mass index on outcome. J Urol 188:138-144

\section{Publisher's Note}

Springer Nature remains neutral with regard to jurisdictional claims in published maps and institutional affiliations.

\section{Submit your manuscript to a SpringerOpen ${ }^{\circ}$ journal and benefit from:}

- Convenient online submission

- Rigorous peer review

- Open access: articles freely available online

- High visibility within the field

Retaining the copyright to your article

Submit your next manuscript at springeropen.com 